Female references in the chronistics of the XVI century.

Reveal and unveil in the Chronicle of Juan de Maldonado

\title{
Referencias femeninas en la cronística del siglo XVI. Desvelo de amor en Juan de Maldonado
}

\author{
Remedios Morán Martín \\ Catedrática de Historia del Derecho \\ Departamento de Servicios Sociales y Fundamentos Histórico-jurídicos \\ Universidad Nacional de Educación a Distancia \\ rmoran@der.uned.es \\ DOI: http://doi.org/10.15366/bp2019.22.026 \\ Bajo Palabra. II Época. № 22. Pgs: 477-500
}


Recibido: 27/07/2019

Aprobado: 02/10/2019

\section{Resumen}

Se mantiene a lo largo de la Historia una contradicción entre dos temas: la valoración de la mujer y su silencio en las fuentes, así como el sentimiento de amor y su frustración por diversos motivos, generalmente por ser amores prohibidos. En este trabajo se intenta indagar en lo que hay de este tema en las obras de Juan Maldonado, De motu hispaniae y Sommium alejado del tema inicial de la obra, sobre las Comunidades de Castilla.

Palabras clave: Juan Maldonado, María de Rojas, mujer, sueños ficticios.

\section{Abstract}

Over the course of history, a contradiction between two themes has remained: the valuation of women and silence of women in sources, for the one hand, and feeling of love and frustration for differents reasons, generally because of forbidden loves, for the other hand. In this paper we try to investigate the importance of these two subjects in the works of Juan Maldonado, De motu hispaniae and Sommium, both so distant from the initial subject of the works: the Commnunities of Castile.

Keywords: Juan Maldonado, María de Rojas, Woman, fictional dreams. 


\section{Planteamiento}

Socialmente mantenemos a lo LARgo de la Historia una contradicción entre dos temas: la valoración de la mujer y su silencio en las fuentes, así como el sentimiento de amor y de frustración por diversos motivos, generalmente por ser amores prohibidos. Pero de repente, en un documento de aplicación del Derecho, en una crónica, en un informe, en cualquier texto aparentemente ajeno al sentimiento amoroso, descubrimos entrelíneas una pasión oculta y eso da un carácter diferente al mismo, que nos permite un análisis desde perspectiva muy distinta a la que inicialmente fue concebido o quizás fue precisamente concebido para ello y ha pasado desapercibido para el otro.

Este es el caso que nos ocupa, en el que tras un análisis de las Crónicas y las llamadas Historias, de época de Carlos I, me centraré de modo especial tanto la crónica de Juan de Maldonado, De motu hispaniae como su opúsculo Sommium, cuya interpretación intento en las páginas que siguen.

\section{El silencio de las fuentes. Búsqueda de una interpretación en el Derecho común}

Lo que principalmente los incita a ser valientes y esforzados es, que no hacen sus escuadras y compañías de toda suerte de gentes, como se ofrecen acaso, sino de cada familia y parentela aparte. Y al entrar en la batalla tienen cerca sus prendas más queridas, para que puedan oír los alaridos de las mujeres y los gritos de los niños, y éstos son los fieles testigos de sus hechos y los que más alaban y engrandecen. Cuando se ven heridos, van a enseñar sus heridas a sus madres y a sus mujeres, y ellas no tienen pavor de verlas ni de chuparlas, y en medio de la batalla les llevan refresco y los van animando.

De manera que algunas veces, según ellos cuentan, han restaurado las mujeres batallas ya casi perdidas, haciendo volver los escuadrones que se inclinaban a huir, con la constancia de sus ruegos, y con ponerles delante los pechos, y representarles el cercano cautiverio que de esto se seguiría, el cual temen mucho más impacientemente por causa de ellas: tanto, que se puede tener mayor confianza de las ciudades que entre sus rehenes dan algunas doncellas nobles. Porque aún se persuaden que hay en ellas un no sé qué de santidad y prudencia, y por esto no menosprecian sus consejos, ni estiman en poco sus respuestas. 
Así lo vimos en el imperio del divino Vespasiano, que algunos tuvieron mucho tiempo a Veleda en lugar de diosa. Y también antiguamente habían venerado a Aurinia y a otras muchas, y esto no es por adulación ni como que ellos las hicieron diosas, sino por tenerlas por tales ${ }^{1}$.

Con estas palabras describía Tácito la percepción que tenían los romanos sobre la participación de las mujeres en la batalla en el caso de los pueblos germanos.

Esta visión de la participación real de las mujeres en la guerra nos es transmitida por numerosas referencias en el mundo clásico, tanto de su participación activa, como de la transmisión de valores a los hombres, sean hijos o maridos, para provocar el fortalecimiento de la moral del ejército, en general, por lo tanto, aún en la mente del soldado más ajena al amor en el momento de la guerra, estas visiones recogidas en diferentes relatos, llevan a introducir a la mujer en el alma del guerrero para conseguir su fortalecimiento.

Si bien es una obra de ficción, es paradigmática Lisistrata, de Aristófanes (s. V a. de C.) que en cierta medida su espíritu es reproducido entre nosotros cuando Salustio escribe:

Después que en ese lugar se descubrió que Pompeyo se aproximaba con un ejército hostil, como quiera que los ancianos les incitaban a la paz y a hacer lo que les mandase, [las mujeres] al no prosperar su negativa, tomaron las armas sin contar con los hombres y, una vez ocupada una posición lo más segura posible junto a $(\ldots)^{2}$ afirmaban que aquellos estaban privados de patria, de madres, y de la libertad: que allí aguardaba a los hombres la cría de sus hijos, su descendencia y las restantes labores propias de las mujeres (...) Por todo lo cual encendidos los jóvenes, despreciando los acuerdos de los mayores... (se levantan en guerra contra los romanos) ${ }^{3}$.

Se podrían poner numerosos ejemplos de la participación de la mujer en las revueltas y en la Guerra desde la antigüedad clásica ${ }^{4}$ hasta la época que aquí ana-

1 Tácito, Cayo Cornelio, La Germania, Trad. de Carlos Coloma, M. Aguilar editor, Madrid, 1945, pp. 483-484.

2 En otras ediciones “cerca Meo[briga]", Salustio, Historias, II, 92.

3 Rodríguez Horillo, Miguel Ángel, "Las Historias de Salustio y los acontecimientos del año 75 a. C. en Hispania (fragmento I 125, II 89-97 M)", en Palaeohispanica 12, 2012, pp. 109-139, la traducción del texto citado en p. 133.

4 Relata Plutarco, de forma breve, el levantamiento del esclavo tracio Espartaco (c. 74 a. C.), contra Roma y en las escasas páginas que le dedica habla en varias ocasiones tanto de la mujer de éste como de otras mujeres que ofrecían sacrificios a los dioses para obtener su favor contra los enemigos: Plutarco, Las vidas paralelas, III, traducidas de su original griego al castellano, por el consejero de Estado D. Antonio Ranz Romanillos, Imprenta Nacional, Madrid, 1822, pp. 242 y ss. con motivo del relato de la vida de Marco Craso y las guerras civiles de su momento, http://books.google.es/books?id=_Zv5iD0XWEoC\&dq=espartaco\&lr=\&as_brr=1\&hl=es\&p$\mathrm{g}=\mathrm{PA} 242 \&$ redir_esc=y\#v=onepage $\& \mathrm{q}=$ mujeres $\& \mathrm{f}=$ false (consulta: 5 -II-2014). Un excelente estudio sobre este tema en Pérez Rubio, Alberto, "La mujer y la guerra en el Occidente europeo (siglos III a. C.-I d. C)", en Jordi 
lizamos del siglo XVI, en plena Guerra de las Comunidades, o en Guerras y movimientos populares posteriores, siendo quizás la Guerra de la independencia la más significativa entre las propias del Antiguo régimen, en las cuales está muy contrastada la participación de la mujer, tanto en las mismas batallas, como en otras actividades importantes como enfermeras, espías, confidentes e incluso con hechos heroicos algunos de ellos de todos conocidos como parte del imaginario popular ${ }^{5}$; no obstante de su participación activa en diferentes aspectos, nos llega a veces más el mito creado en torno a una figura que sus propios hechos. Son los casos de Aspasia de Mileto, Olimpia, Livia Drusa o Friné ${ }^{6}$, entre otras, respecto del mundo greco-romano; o bien María de Padilla en la Guerra de las Comunidades o Manuela Malasaña en la de la Independencia.

Esa presencia que se percibe tan clara en la literatura clásica no es tan evidente entre los siglos XIII al XVIII, quizás porque estamos ante una percepción de la mujer muy diferente, característica del Derecho común, debido a la influencia del Derecho canónico y de la ideología de la Iglesia, que da un alto valor social a la mujer, pero un escaso valor jurídico, por lo que se tiende al encubrimiento de su posición en cualquier aspecto de la vida pública, salvo mujeres de gran relevancia, de alta clase social, como pueda ser el caso de María de Padilla ${ }^{7}$ en el tema que aquí nos ocupa.

El tema de la mujer en este periodo está siendo objeto de múltiples estudios en los últimos decenios, por lo que no voy a entrar en su análisis, solo constatar cómo con la recepción del Derecho común se van perfilando dos imágenes de la mujer (Eva, pecadora por la que el mundo sufre y María, redentora como madre) y un mismo imaginario: subordinación de la mujer al hombre ${ }^{8}$, que se refleja en

Vidal y Borja Antela (eds.), Más allá de la batalla. La violencia contra la población en el mundo antiguo, Libros Pórtico, Zaragoza, 2013, p. 97-126, con una bibliografía actualizada.

5 Hay una amplia bibliografía sobre el tema, vid., Reder Gadow, Marion, "Mujeres en las Barricadas durante la Guerra de la Independencia (1808-1814): la rondeña María García 'La Tinajera”, en Dossiers feministes, 15, 2011 (Ejemplar dedicado a: Mujeres con mayúsculas. Barricadas, salones y escritorios (siglos XVII-XIX), pp. 9-25, entre la bibliografía por ella citada, vid., Domergue, Lucienne, "Goya, las Mujeres y la Guerra contra Bonaparte", en La Guerra de la Independencia en Málaga y su provincia (1808-1814), Servicio de Publicaciones del CEDMA, Málaga, 2005, pp. 231-248; Jiménez Bartolomé, Ana María, "Las mujeres en la Guerra de la Independencia: propaganda y resistencia", en Ocupació i resistencia a la Guerra del Francès (1808-1814), Biblioteca de Cataluna, Barcelona, 2005, pp. 247-256; Fernández Jiménez, María Antonia, "La mujer en la guerra”, en España 1808-1814. La Nación en armas, Secretaría General Técnica del Ministerio de Defensa y Sociedad Estatal de Conmemoraciones Culturales, Secretaría General Técnica del Ministerio de Defensa y Sociedad Estatal de Conmemoraciones Culturales, Madrid, 2008.

${ }^{6}$ Pérez-Prendes, José Manuel, "El mito de Friné", en Cuadernos de Historia del Derecho, Cuadernos de historia del derecho (en homenaje a don Manuel Torres López.) 6, I y II, 1999-2000, pp. 211-232; id., "El mito de Friné. Nuevas perspectivas", en Anuario de la Real Academia de Bellas Artes de San Telmo no 5, 2005, pp. 33-46.

7 Vid. Id., "María Pacheco, comunera por otro entusiasmo", en Szaszdi León Borja, Istvan y Galende Ruiz, María Jesús, Imperio y tiranía. La dimensión europea de las Comunidades de Castilla, Universidad de Valladolid, 2013, pp. 385-410.

8 Estas ideas están recogidas en Muñoz Fernández, Ángela, "Introducción”, en Las mujeres en el cristianismo medieval, Ed. Laya, Madrid, 1989, especialmente pp. 6-8, en esta obra se recogen diferentes aspectos sobre la mujer en 
los tratados de la época sobre la condición de la mujer, siendo paradigmáticos el de Francecs Eiximenis, Libro de las donas ${ }^{9}$, Alonso de Madrigal en De optima politia ${ }^{10}$ o el de Fray Luis de León, La perfecta casada ${ }^{11}$, por citar solo dos obras muy significativas de estos siglos.

Podría ser ésta una explicación de la falta de presencia femenina, por ejemplo, también en la cronística de la época, pero hay que adentrarse más en su lectura y en las diferentes versiones que de la época de Carlos I hacen los cronistas para acercarnos algo más a la percepción de lo femenino, con independencia de la participación efectiva de mujeres concretas en revueltas o en actos de la vida política, en general.

En este trabajo voy a centrarme en una de las primeras obras de época de Carlos I, que no se adapta exactamente al concepto de crónica ni de historia, sino que sigue un estilo dialogado, diferente, y que se centra en el tema de las Comunidades de Castilla, la obra de Juan Maldonado, De motu Hispaniae (c. 1525) ${ }^{12}$, si bien su publicación es muy posterior.

En esta obra, como en crónicas e historias, se puede percibir de un modo diferente el tema que aquí se aborda, tanto por el estilo propio del cronista con el

la Edad Media desde el prisma del cristianismo. Muy bien reflejada la vida de las mujeres según su estado civil, en Vigil, Mariló, La vida de las mujeres en los siglos XVI y XVII, Siglo XXI, Madrid, 1986; Más recientemente, Fuente, Ma Jesús y Morán, Remedios (Eds.), Raíces profundas de la violencia contra las mujeres (Antigüedady Edad Media), Ed. Polifemo, Madrid, 2011; desde el punto de vista que aquí se analiza, especialmente los trabajos de Tamayo Acosta, Juan José, "Las fuentes religiosas cristianas: La Biblia y los padres de la Iglesia”, en ibid., pp. 27-44 y Pérez-Prendes, José Manuel, “Génesis, 2.25”, en ibid., pp. 407-432.

9 Sobre esta obra, vid., Cervera Vera, Luis, Francisco de Eiximenis y su sociedad urbana ideal, Col. Torre de la Botica, Swan, Real Sitio de San Lorenzo de El Escorial, MCMLXXXIX, especialmente pp. 61-62; Martín, José Luis, La mujer y el caballero: estudio y traducción de los textos de Francecs Eiximenis, Edicions Universitá de Barcelona, 2003.

${ }^{10}$ Indirectamente es un tratado sobre las mujeres, excluyéndolas de la vida política y desde una perspectiva masculina, vid. El 'De optima politia' de Alonso de Madrigal el Tostado, traducción y estudio preliminar de Juan Candela Martínez, https://revistas.um.es/analesumderecho/article/download/103091/98071 [fecha de consulta: 12/04/2019]. Asimismo, puede verse sobre el tema, Cátedra, Pedro, Del Tostado sobre el amor, Stelle dell'Orsa, Barcelona, 1986.

11 La primera edición está impresa en la Imprenta de Juan Fernandez, Salamanca, 1583.

12 Esta fecha la aporta Ma Ángeles Durán, si bien el manuscrito que se conserva en la Biblioteca de El Escorial está dedicado a Felipe II y fechado en 1540, pero no parece que fuera escrito en esta fecha, Maldonado, Juan, De motu Hispaniae. El levantamiento de España, Traducción, notas e introducción de María Ángeles Durán Ramos, Centro de Estudios Constitucionales, Madrid, 1991, cito por esta edición todas las referencias a la obra de Maldonado. Existen otras ediciones: la primera que se hizo de la obra es de José Quevedo, La revolución comunera. El movimiento de España, o sea historia de la revolución conocida con el nombre de las comunidades de Castilla, escrita en latín por el presbitero Juan Maldonado y traducida e ilustrada por el presbitero don José Quevedo, bibliotecario del Escorial, 1840 (existe nueva edición con introducción de Valentina Fernández Vargas, Ed. Centro, Madrid, 1975); El "De motu Hispaniae" de Juan de Maldonado, estudio y edición crítica de Manuel Martínez Quintana, Editorial Universidad Complutense de Madrid, 1988 (Tesis doctoral, Departamento de Filología clásica, Facultad de Filología, UCM, 2015, está en pdf en el repositorio de la UCM. Cito esta obra por esta ed.) Véase también sobre su significado, Smith, Paul Stephen, A humanist history of the "Comunidades" of Castile: Juan Maldonado's De motu hispaniae, University of British Columbia, 1987 https://circle.ubc.ca/ handle/2429/26922? show=ful [consulta: 12-02-2019]. 
más libre del autor literario, sin dejar de tener en cuenta, desde el punto de vista de nuestro análisis, que los cronistas de su momento fueron también historiadores o autores de obras de diferentes estilos, y, como nuestro autor, con participación activa en la política, que, por lo tanto, presenta un interés de múltiples visiones para el tema de la visión de la mujer, como se irá exponiendo.

\section{Mujeres en las Crónicas sobre las Comunidadesł presentes, pero silenciadas}

En el amplio relato de Pedro Mexía sobre las Comunidades, hace referencia a la visita del rey a su madre, en Tordesillas, antes de ir a las Cortes de Santiago y la Coruña y alude a que "el común y vezinos della huvieron gran pesar y sentimiento y començaron por el pueblo a tratar dello”; más adelante, relatando el levantamiento de Toledo:

"La proçesión se hizo el día que estaba señalado, con muy grande plazer y feruor del pueblo y con muchos menospreçios y murmuraçiones de los contrarios; de lo qual quedaron de allí adelante tan desvergoçados e atreuidos los de la Comunidad, que la justiçia tenía ya muy poca fuerça, y en todo avía desorden y confusión y comunmente se haçía y ordenaba lo que Hernando de Avalos y Juan de Padilla querían, en el regimiento y fuera dél (...) Y luego fueron a las posadas del corregidor el qual visto lo que pasava andava mandando dar pregones que todos se fuesen a sus casas y haçiendo otros mandatos sin fruto ni efecto..."; ampliada la revuelta "Y çierto fueron grandes ocasiones de los males que suçedieron. Señaladamente, en la gente popular de algunas çiudades de Castilla cresçió sin parar el atreuimiento, trocándose las murmuraciones y desvergüenças pasadas ya dichas en desacato y osadías intolerables... etc. ${ }^{13}$

Si bien las mujeres simples libres o no privilegiadas están silenciadas y quedan perdidas entre alusiones a "la gente", "los del pueblo", "murmuraciones", etc., no lo son tanto las de clase noble o mujeres privilegiadas, que sí aparecen en las Crónicas, unas veces para ser valoradas y otras denostadas, según la ideología preponderante del cronista o historiador estudiado, siendo, en todos los casos, salvada de la crítica la actitud de la reina Juana a la que visitaron los comuneros en Tordesillas, que es casi unánimemente tratada como fiel a su hijo, a pesar de las presiones ejercidas sobre ella, relatadas con mayor o menor extensión por los diferentes cronistas, así como el tratamiento que unos y otros dan a la actitud de los comuneros, en el caso de Mexía considerándolos como tergiversadores de la

\footnotetext{
${ }_{13}$ Mexía, Pedro, Historia del Emperador Carlos V, escrita por su cronista el magnifico caballero --, Ed. y estudio de Juan de Mata Carriazo, Espasa Calpe, Madrid, 1945 (cito por esta edición), pp. 134, 142-143, 149-150, respectivamente.
} 
realidad de las palabras dichas por la reina, si bien reconociendo su actitud a favor de su hijo ${ }^{14}$.

Asimismo aluden en alguna ocasión a mujeres de alta clase social, en diferente sentido, como María Pacheco "mujer de Juan de Padilla, hermana del marqués de Mondéxar; que fue vna muger de muy inquieto y bullicioso ánimo, y que presumió sienpre de muy valerosa y de altos pensamientos, que es vna pasión que á hecho a muchos onbres hazer grandes desatinos y atrevimientos" ${ }^{15}$, que no suele ser del agrado de los cronistas, posiblemente por no acatar las normas sociales del momento, por lo que se menciona bien cuando trata de los desmanes que hacía en Toledo quedando como gobernadora en ausencia de su marido o cuando arenga a los comuneros; o en otro sentido, por estar más cercana a los paradigmas marcados para la mujer noble, como la condesa de Alba, que posibilitó que no ajusticiaran y quemaran las casas de los procuradores de Zamora; bien las mujeres principales que acompañaban a la reina Juana, entre ellas Catalina de Figueroa (hija de Lope Zapata, mujer del comendador Luis de Quintanilla) ${ }^{16}$.

Posiblemente sea Fray Prudencio de Sandoval el que más se detiene en el relato de linajes y por lo tanto, de la relación entre las mujeres de alta clase social y los hombres de tal rango que van apareciendo en los hechos. Así, por ejemplo, al relatar la genealogía de los reyes ${ }^{17}$, pero también de otras mujeres, como se verá abajo.

Por otro lado, entre las escasas referencias en que aparecen las mujeres en las crónicas e historias del momento, hay alguna alusión a las mujeres y niños como víctimas, lo que de nuevo nos lleva a algunos fragmentos de la literatura clásica, como Tácito, en torno a la guerra y a sus víctimas, ajenas a los soldados. Esto tiene un doble sentido: si fueron víctimas es porque en muchas ocasiones estuvieron presentes, salieron a la calle, entraron en sus casas, arrasaron sus campos y huertos, fueron heridas, violadas y asesinadas, etc., no solo fueron terceros en la discordia y quedaron los niños huérfanos y las mujeres viudas ${ }^{18}$.

\footnotetext{
${ }_{14}$ Ibid., pp. 168-169, 213-215.

15 Ibid., pp. 145, 227, 235, 257; "doña María Pacheco, que fue un tizón del reino”, a decir de Sandoval, Fr. Prudencio de, Historia del Emperador Carlos V, rey de España, La Lectura. Biblioteca de obras selectas, bajo la dirección de D. Gregorio Urbano Dargallo, Madrid, 1846, II, p. 51. (cito por esta edición); "El marido de su marido", frase con la que se ha caracterizado muy habitualmente a María Pacheco o bien su opinión sobre su bravura de carácter frente a lo habitual de las mujeres castellanas del momento, desde que la describiera Guevara, Fray Antonio de, Epístolas Familiares, Ed. de José María Cossío, Madrid, 1950, I, epístola 51, p. 321. Véase también Relación del discurso de las Comunidades, Edición, introducción y notas de Ana Díaz Medina, transcripción de Jacinto de Vega, Junta de Castilla y León, Valladolid, 2003, pp. 19 y 20.

${ }_{16}$ Mexía, Pedro, Historia, o. c., pp. 150-151, 167-170, respectivamente.

17 Sandoval, Fr. Prudencio de, Historia del Emperador Carlos V, o. c., II, p. 27-28, passim.

${ }^{18}$ Los desmanes contra mujeres se apuntan incluso en la crónica de Francesillo de Zúñiga, bufón de Carlos I y que como tal pasa de puntillas por las Comunidades, pero que, sin embargo, no puede menos que decir: " $y$
} 
La presencia femenina en el relato de Fray Prudencio de Sandoval está ya en las primeras quejas que los de Toledo exponen ante el Emperador, de manera que ya se quejan de que: "Demás desto, tenían los flamencos en tan poco a los españoles, que los trataban como a esclavos, y los mandaban como a unas bestias, y les entraban las casas, tomaban las mujeres, robaban la hacienda y no había justicia para ellos" ${ }^{19}$.

Así, ya iniciadas las Comunidades, la violencia contra mujeres y niños la constata Pedro Mexía cuando trata de los hechos de Antonio de Fonseca en Medina del Campo, donde la villa se abrasaba "porque ardió toda la mayor parte de la plaza, y el monasterio de San Francisco, y Santo Antolín, y gran parte de las calles comarcanas a esto, con toda la riqueza y ropa, y oro y plata de los mercaderes y vezinos que en ella estauan, que fué vna suma innumerable. $Y$ ansí mesmo fueron quemadas algunas mugeres y niños; de manera que ello fué vna de las más lastimeras y tristes cosas que he visto" ${ }^{20}$. Y en el mismo sentido Fray Prudencio de Sandoval: "Era cosa lastimosa ver las gentes, mujeres y nińos llorando y gimiendo desnudos, sin tener dónde se acoger ni con qué cubrir sus carnes, dando voces al cielo y pidiendo a Dios justicia contra Antonio de Fonseca" ${ }^{21}$. Hasta el punto debieron ser los hechos alarmantes y habituales, que en la carta que escriben los de Medina del Campo al cardenal, exponiéndoles sus quejas, relatado por Sandoval, también se relatan dichos actos contra mujeres, niños y viejos ${ }^{22}$.

Pasaje también muy duro es el que relata el mismo Mexía relativo a la toma de Mora, villa cercana a Ocańa, en la cual ante el ataque de las fuerzas del Emperador,

con estas necesidades y otras tales hicieron gran dańo y estrago en la tierra, matando y robando muchas gentes, quemando lugares, deshonrando la mujeres casadas y doncellas”, Zúńiga, Francesillo de, Crónica burlesca del emperador Carlos V, Edición, introducción y notas de Diane de Avalle-Arce, ed. Crítica, Barcelona, 1981, p. 80.

19 Sandoval, Fr. Prudencio de, Historia del Emperador Carlos V, o. c., II, p. 9.

20 Mexía, Pedro, Historia, o. c., p. 162.

21 Sandoval, Fr. Prudencio de, Historia, o. c., II, pp. 351.

22 "Porque a ninguno en toda la villa le queda que comer, y no tiene otro remedio sino ir a buscar otra nueva tierra para hacer nueva población, como hicieron los bárbaros en los tiempos antiguos que ocuparon a Italia, o crueldad, entraron a las casas y cortaban los dedos de las manos a las mujeres para sacarles las sortijas y aljorcas y manillas; y otras cuchillaban por desnudarlas presto las ropas que traían, y a otras dieron muchas saetadas, espingardadas, y mataron con escopetas hartos niños. Y hechos estos insultos, porque no les quedase algún linaje de crueldad por ejecutar, robaron clérigos y ancianos, y ponían para hacerlo las manos sacrílegas en ellos (...) Pedirle queremos sienta vuestra seńoría la ofensa de Dios y traición a la corona real y nuestra perdición, y tan inestimable, que no sufre satisfación y libertad hecha a vuestra señoría de la ira de Dios, que suele provocar los clamores y lágrimas que derraman las mujeres y nińos de toda esta villa. Porque las calles que quedaron todas están llenas de gritos y maldiciones, pidiendo a Dios justicia y venganza", Sandoval, Fr. Prudencio de, Historia, o. c., II, pp. 361-362. Posteriormente escribe Medina también cartas a otras ciudades con similar contenido, p. 365. Más adelante, al relatar los hechos de Baeza: "Y fue tanta la destruición y mortandad, que contaban haber muerto abrasados cerca de dos mil personas, entre hombres, mujeres y niños; y el daño y destruición que se hizo en el pueblo, permanece hoy día en muchas casas deste lugar, que están caídas y con las señales del fuego, que las han querido dejar así en señal de su lealtad", p. 371, passim. 
mujeres y nińos se encerraron en la iglesia, cerrando las puertas menos una en la que pusieron pólvora para su defensa, pero pendida ésta empezó a arder la iglesia y murieron cerca de tres mil personas ${ }^{23}$. Relatos como éste son recogidos por diferentes cronistas, no voy a incidir más en ello.

Si bien en la mayoría de los pasajes no aparecen las mujeres individualizadas, sí hay numerosas referencias a quema y derribo de sus casas por parte de los comuneros (menos frecuentes por parte de los realistas, debido en gran medida al perfil de los mismos), en Arévalo, Valladolid, Medina del Campo, Toledo, etc. por lo que obviamente, afecta no solo a los personajes masculinos citados, sino también a sus mujeres e hijos $^{24}$.

En el plano contario, es Fray Prudencio de Sandoval quien con más frecuencia relata también algunos hechos de actuaciones de mujeres en el levantamiento comunero, así en Segovia, se adhieren a los hombres en la lucha contra el alcalde realista Rodrigo Ronquillo ${ }^{25}$. O bien, cuando relata los hechos de la mujer de Negrete en la defensa del Alcázar de Madrid, en este caso a favor del rey:

De la gente de la villa era capitán un hombre que se llamaba Negrete. Determinaron de minar el alcázar por cuatro partes, y sintiendo los de dentro que los minaban, arrojaban contra ellos muchos más tiros, y dieron con uno a un hombre que sacaba tierra con una espuerta y matáronle, y por esto dejaron de minar de día, y minaban de noche con antepechos y mantas y lo más a salvo que podían, y ponían encima de ellas los hijos y parientes de los que dentro estaban, porque por no matarlos no tirasen a los que debajo de las mantas iban.

Pero con todo eso, la mujer del alcalde, que dentro estaba, se daba tan buena maña en ayudar, y aún a animar que peleasen, que no hacía falta su marido, de tal suerte que ella era el amparo y defensa de la fortaleza.

Los de la villa les enviaron a requerir que se diesen; si no, que no entraría ni saldría hombre que no fuese muerto o preso. Ella respondió que en balde trabajaban, que no pensasen que por estar el alcalde ausente, ella ni los demás habían de hacer cosa fea ni en deservicio del rey. Que todos estaban determinados de antes morir defendiéndose, que cometer semejante traición. Que donde ella estaba, no había de hacer falta el alcalde su marido.

Como la Comunidad oyó esto, alteróse grandemente, y dijo a voces: «Mueran, muramos todos ${ }^{26}$

${ }^{23}$ Mexía, Pedro, Historia, o. c., pp. 247-248.

${ }^{24}$ Fr. Prudencio de Sandoval, refiriéndose a la defensa de la villa de Fuentes de Valdepero, relata que "aunque se defendieron valerosamente, ayudando no poco las mujeres, se huvieron de rendir (...) Usó aquí el Obispo (Acuña) de una bondad grande, con ser un sangriento en otras cosas, que no consintió que tirasen a las mujeres los suyos, porque sino todas murieran”, o. c., II, p. 92

25 "Hizo Segovia alarde de la gente de guerra que tenía para defenderse de Ronquillo. Y halló doce mil hombres con tanto ánimo, que aun hasta las mujeres y los niños tomaban las armas. Hicieron fuertes palenques, hondos fosos, encadenaron las calles. Y la ciudad de Ávila les ayudaba como si fuera causa propia”, Fr. Prudencio de Sandoval, o. c., II, p. 132.

26 Sandoval, Fr. Prudencio de, o. c., II, p. 141-142. 
Similar valor le da a otros relatos de mujeres que, en este caso, defienden el honor del marido frente a los ultrajes de comuneros, como el caso de Inés de Barrientos Manrique, en Cuenca ${ }^{27}$.

Entre las crónicas elegidas, podrían citarse otros casos, no demasiado diversos, porque en gran medida las fuentes son las mismas y es conocida la técnica de utilización de noticias de unos cronistas por otros, pero los temas siempre son recurrentes: generales, sin apenas diferenciar rostros, nombres y figuras femeninas, conscientes todos de su presencia y de su inserción en los acontecimientos, porque como decía Alonso de Madrigal años antes: "La naturaleza de la tierra, las haciendas, las moradas, los hijos, las mujeres... (son cosas que) engendran el entrañable amor a la República, donde es cierto que a los ciudadanos que estas cosas faltan, les falta amor, y éstos a quienes falta el amor, son amigos de novedades, y los amigos de novedades, son enemigos de la paz y los enemigos de la paz son inclinados a la perdición de los hombres y de los pueblos" 28 .

La tónica general, no hace falta más extensión, es la ausencia de lo femenino en las crónicas y en las historias redactadas durante el siglo XVI, la ausencia de sus vivencias, la ausencia de sus ideas y la ausencia de su actuación individualizada, excepto alguna mujer particular, como se ha dicho. La guerra siempre ha estado asociada con una función masculina, y son válidas para la mayoría de los tiempos las palabras de Francine D’ Amico:

Si aún tenemos que hablar de "mujeres y la guerra", subraya la generalización de nuestra construcción de la guerra. La guerra ha sido percibida como dominio de los hombres, una tarea masculina para la cual las mujeres pueden servir como víctima, espectador o premio. A las mujeres se les niega la participación, estuvieron presentes pero silenciadas ${ }^{29}$.

\footnotetext{
27 "Levantóse Cuenca, como las demás ciudades, y se hicieron en ella semejantes desatinos. Fue aquí capitán de la Comunidad un Calahorra, y con él otro, frenero, a los cuales obedecía la ciudad como a seńores. Y siendo en esta ciudad y en el reino persona principal y gran parte Luis Carrillo de Albornoz, señor de Torralba y Beteta, le perdieron el respeto de tal manera, que no viviera si no disimulara y usara del mucho valor y prudencia que tenía. Y llegó el atrevimiento a tanto, que yendo por la calle en su mula, un pícaro de la Comunidad se le puso a las ancas, diciéndole: Anda, Luis Carrillo, burlando dél, y hubo de pasar por ello, porque el tiempo no daba lugar a otra cosa.

Era casado Luis Carrillo con dońa Inés de Barrientos Manrique, mujer varonil, y queriendo vengar la injuria hecha a su marido y quitar aquel oprobrio de la ciudad, convidó a cenar a los capitanes comuneros, y cargándolos de buen vino, los hizo llevar a dormir cada uno a su aposento. Sepultados ya en el sueńo y en los vapores del vino, mandó que los criados los matasen, y muertos, los colgaron de las ventanas de la calle; que fue una hazaña digna de esta memoria y de quien la hizo", Sandoval, Fr. Prudencio de, o. c., p. 372.

${ }^{28}$ Madrigal, Alonso de, De optima politia, pp. 19, 36 y 51, apud., Montero Ballesteros, Alberto, "El 'Tractado de Republica' de Alonso de Castrillo (1521)”, Revista de Estudios Políticos, 188, 1973, 143-144.

29 "That we even need to talk about "women and war" underscores the gendering of our construct of war. War has been perceived as men's domain, a masculine endeavor for which women may serve as victim, spectator or prize. Women are denied agency, made present but silenced", Francine D'Amico, "Feminist Perspectives on Women Warriors", en L. A. Lorentzen y J. Turpin (eds.), The Women and War Reader, New York, 1998,
} 
Considero que esta perspectiva es muy sugerente para desarrollar los diferentes aspectos en los que la mujer está inmersa en las Comunidades: que estuvieron presentes, pero silenciadas es obvio e hilo conductor de cualquier explicación de su ausencia en las fuentes cronísticas; que en las guerras han sido víctimas en tan gran medida como los hombres es una afirmación que comparto doblemente, porque fueron asesinadas, violadas, enviudadas e incluso tomadas como rehenes después de las guerras; que fueran premio, está también constatado no solo algunas mujeres de la realeza o de alta nobleza, que fueron casadas con grandes personajes como modo de afianzar las alianzas, sino porque con frecuencia se llevaron a mujeres del enemigo para regocijo de tropas y del servicio de los mandos del ejército, sea cual fuere el campo de batalla.

No tan de acuerdo estoy en que fueran meras espectadoras, porque eso va en contradicción con lo anterior, en primer lugar, y en segundo, porque también con frecuencia tomaron las armas y, además, supondría la ausencia de su colaboración en otras funciones alternativas como espías, portadoras de pertrechos, enfermeras, cocineras, ocultando a hombres en casas, campos, graneros, pajares, etc. pero sobre todo supondría el despojarlas no solo de protagonismo, sino del dolor que la guerra supone para ellas, sus maridos y sus hijos.

Es volvernos de nuevo a lo que nunca fuimos y nunca estuvimos: ausentes de los hechos de cada momento histórico, la ausencia en los relatos es una reducción de la realidad, porque en esta revolución, en esta guerra y en todas las guerras, fueron igualmente víctimas, pero además como sublimación de su desgracia galardón para el enemigo, desgarrándolas de su casa, su familia y su patria y en el caso de algunas grandes mujeres, también última venganza, como en el caso de María Pacheco ${ }^{30}$.

\section{Juan Maldonado: una crónica y un sueño}

JuAn Maldonado, PREsbítero conquense (nació en Bonilla, del partido judicial de Huete, Cuenca), aunque de procedencia salmantina, donde estudió, perteneciente al clero ilustrado de su momento y relacionado con los sectores de la élite burguesa castellana, a la que dedica parte de su $\mathrm{obra}^{31}$. Esta posición cercana a la

p. 119, apud. Alberto Pérez Rubio, "La mujer y la guerra en el Occidente europeo (siglos III a. C.-I d. C)", o. c., p. 97.

30 Vid. especialmente sobre este aspecto Mendonça, Manuela, "Uma mulher no exílio: María de Padilha e Portugal", en Monarquía y revolución: en torno a las Comunidades de Castilla. I Simposio Internacional de Historia Comunera, Valladolid, 2009, pp. 259-275.

${ }^{31}$ Nació entre 1483-1486 y murió en los primeros meses de 1554, García García, Heliodoro, El pensamiento comunero de Juan Maldonado, Madrid, 1983, pp. 5-6, cito por esta obra, si bien es un extracto de su Tesis doctoral, El pensamiento erasmista, comunero, moral y humanistico de Juan Maldonado, Universidad Complutense de Madrid, Facultad de Filosofía y Ciencias de la Educación, 1983. 
burguesía adinerada y a la nobleza será fundamental en su pensamiento, que si bien está abierto a todas las corrientes de su momento, no duda en acercarse rápidamente a las doctrinas oficiales de su tiempo, vaivenes que se advierten en su amplia obra.

Por otra parte, las dos obras de Maldonado que aquí analizo, De motu hispaniae y Sueño ${ }^{32}$, son novedosas por su estilo en España: el primero por ser un diálogo, que si bien es un género ya utilizado para otro estilo de obras, no lo es para una crónica o para un relato histórico hasta entonces en España; el segundo, el Sueño, porque no abundó demasiado antes del siglo XVI, aunque se había utilizado alguna vez en la literatura latina, y con mucha posibilidad Maldonado evocó el "Sueño de Escipión”, de Cicerón ${ }^{33}$, por lo que utiliza en sus obras tanto el diálogo, como el sueño, lo que lo inserta plenamente entre los escritores más avanzados estilísticamente de su momento, permeable a las influencias del Renacimiento italiano y a sus recursos, si bien no puede obviarse su pensamiento cercano a los comuneros ${ }^{34}$.

\subsection{Mujeres y mujer en De motu Hispaniae de Maldonado}

Como le pasara a Juan Ginés de Sepúlveda, la Crónica de Maldonado denominada De motu hispaniae, a la que he hecho ya referencia en este trabajo no fue publicada hasta el siglo XIX, quizás por su tendencia inicial por el partido comunero (luego abandonado, como hicieron sus protectores), así como por estar escrita en latín. Me detengo en analizar la perspectiva desde la que Maldonado inserta a la mujer en su crónica: no hay que olvidar que fue redactada por un personaje que vivió en primera persona los acontecimientos, al estar muy relacionado profesional y personalmente con algunas de las familias más significadas de los partidarios iniciales del movimiento comunero.

Dos cuestiones me llaman la atención en De Motu de Maldonado: en primer lugar es significativo, a diferencia de otras crónicas, su forma dialogada, en el que el cronista se inserta entre los personajes que relatan los hechos a unos extranjeros, lo que ya da pie a que el discurso sea diferente a una exposición lineal de los acontecimientos, que, por otro lado, el mismo autor le da un valor adicional diciendo que

${ }^{32}$ Maldonado, Juan, Sueño, traducción castellana (Ed. de Miguel Avilés, Sueños ficticios y lucha ideológica en el Siglo de Oro, Editora Nacional, Madrid, 1980, pp. 149-178, con estudio introductorio, pp. 107-148. Cito por esta edición).

33 Cicerón, M. Tulio, Sobre la república, introducción, traducción, apéndice y notas de Álvaro D’ Ors, Ed. Gredos, Madrid, 1984, puede verse especialmente la introducción donde hace repetidas alusiones al sueńo de Escipión, pp. 8, 10-12, 25-28 y en el propio texto ciceroniano, libro VI, pp. 158-171.

34 Vid., especialmente García García, Heliodoro, o. c., y Maravall, José Antonio, Las Comunidades de Castilla, Alianza Universidad, Madrid, 1981, $3^{\text {a }}$ ed., pp. 64-65, cuando relaciona la utilización del concepto de patria y de patres conscriptis a los miembros de la Junta comunera, que no puede considerarse solo un recurso estilístico. 
relata lo que vivió, por lo tanto no existe mediatización de otras fuentes indirectas, documentales o testificales, y teniendo como fin el dar noticia exacta de los hechos a los extranjeros, que introduce en el relato cuando los encuentra en Hospital del rey de Burgos, que alberga a los peregrinos que pasan haciendo el camino de la ruta de Santiago. Con ello consigue una serie de efectos literarios, descargando al relato de la fórmula habitual de hechos históricos que lo pueden llevar a problemas con el poder; además, el personaje que relata los hechos es ajeno al autor, por lo que lo libera de ser acusado de algún delito por estar cercano a los comuneros y, en tercer lugar, al insertar el relato en la ruta más internacional del momento, conectando lo local con lo europeo, máxime al entrar en contacto con un francés, un alemán y un italiano ${ }^{35}$ en su coloquio, además de un toledano ${ }^{36}$.

Por lo tanto nada de lo expuesto es aleatorio porque el relato de los hechos por parte castellana se plantea entre un toledano, con la significación que tuvo Toledo en los acontecimientos (en los que se recrea, por el mismo relato del toledano en muchas ocasiones, lo que aleja al autor de algunos de los episodios más duros de la contienda) y un burgalés (el propio Maldonado), el polo opuesto en las Comunidades en cuanto a su pronta retirada de las mismas y las razones de la burguesía y del Concejo para ello. Estos dos personajes no dejan de evidenciar la actitud de Maldonado de querer en unos momentos acercarse y en otros distanciarse del bando comunero, del que con seguridad debía estar más cerca, pero, como en su vida y obra, intenta mantener un punto de distancia que lo libera de toda sospecha en cualquier caso.

En segundo lugar, desde el punto de vista del análisis que aquí se aborda, desde el principio inserta su relato en un contexto femenino: el encuentro de los tres viajeros en el Hospital del rey, aledaño al Monasterio de las Huelgas de Burgos, monasterio cisterciense femenino, cuyo origen explica e incluso acerca al lector, al introducir aspectos relacionados con la abadesa.

A pesar de que el burgalés es el relator de los hechos, Maldonado, no logra apartarse de los acontecimientos al modo tradicional ${ }^{37}$, el halo de lo femenino aparece con más frecuencia que en otras crónicas e historias analizadas y puede apreciarse la presencia de mujeres en ámbitos diferentes a los que aparecen en otros autores, po-

\footnotetext{
35 El personaje italiano es interesante, porque Maldonado a través de las referencias a él o sus intervenciones, lo utiliza para conectar a España con la cultura clásica, recreándose en la explicación de la España romana, sus riquezas y valores, como el italiano en su exposición de la importancia de la irradiación de la cultura clásica en Europa.

${ }^{36}$ Es significativo que elija a un toledano entre los que participan en el coloquio, dada la trascendencia de Toledo en la revuelta, vid., Martínez Gil, Fernando, La ciudad inquieta. Toledo comunera. 1520-1522, Instituto provincial de Investigaciones y estudio toledanos - Diputación provincial de Toledo, 1993.

37 Acertadas apreciaciones sobre diferentes aspectos recogidos en la De motu Hispaniae de Maldonado, en Jerez, José Joaquín, Pensamiento político y reforma institucional durante la Guerra de las Comunidades de Castilla (15201521), Marcial Pons, Madrid, 2007, passim.
} 
siblemente por su influencia italianizante. Sin ánimo de exhaustividad: al referirse, conectando con las peticiones comuneras, al pago de un ducado por cada hombre y mujer, los pagos según los hijos e hijas ${ }^{38}$; se refiere a la mujer de Diego Osorio que presencia los hechos cuando los acosaron los pecheros en Burgos, que relata pormenorizadamente ${ }^{39}$; la contundente y atroz ferocidad contra niños y mujeres en cuantos lugares se extendía la revuelta, etc.

Sin embargo, ninguno tan realista y tan relacionado, por otra parte, con las palabras con las que se inicia este texto, que el referido a los hechos de Medina del Campo contra Fonseca:

La destrucción de la ciudad, la violencia a sus esposas e hijos, el descuartizamiento y la muerte (...). Las mujeres mismas, saliendo de sus casas y dejando a sus hijos en medio de las llamas, corrían junto a sus maridos dando alaridos, chillando y gritando tristemente 'Corred varones, luchad los maridos, defended de estos ladrones los cañones, no os preocupéis de vuestras casas y pertenencias, aunque se destruyan, ardan y se quemen, nosotras, mientras seáis libres, mientras libréis a la patria, os procuraremos comida en el telar, el huso y la aguja; por Dios y la Virgen María, no queráis contribuir con vuestra culpa al derribo de las ciudades aliadas y a la dura servidumbre del mísero pueblo ${ }^{40}$.

En definitiva, podrían reiterarse las citas, pero la conclusión sería que, al igual que otras crónicas, la mujer en De motu Hispaniae, está algo más presente que en otras, pero no está individualizada. Incluso cuando habla, poco, de alguna de las más conocidas, como María de Padilla, no tiene un juicio muy benévolo a juzgar por la práctica ausencia del relato, a pesar de tener una tendencia comunera en mayor medida que la mayoría de los cronistas, lo que queda claro en los relatos de Burgos y especialmente del obispo Acuña ${ }^{41}$, cuyo hermano, D. Diego de Osorio, era protector de Maldonado, si bien Diego de Osorio no se afilió claramente al bando comunero desde el principio y fue conocido su cambio de afiliación frente a los comuneros, secundado por Maldonado, que como él tiene un alineamiento con los comuneros en un primer momento y viraje hacia el bando realista seguidamente ${ }^{42}$.

\footnotetext{
${ }^{8}$ De motu Hispaniae, ed. cit. p. 127 y nota 1.

39 Ibid., pp. 152-153.

40 Ibid., p. 199. Si bien este episodio es relatado por la mayoría de los cronistas, ninguno lo hace con tanta vehemencia y realismo como Maldonado. De similar realismo y pormenores es la descripción que hace de las atrocidades en otros lugares, como en la villa de Fuentes, Ibid., pp. 333-334; o en la villa de Mora, Ibid., pp. 379-386, passim. Asimismo es minucioso el relato del levantamiento de las Merindades contra Velasco, en el que también relata un episodio sobre la forma en que fueron sacadas de sus casas un grupo de nobles doncellas y, entre ellas, algunos realistas para eludir el acoso de los pecheros, ibid., pp. 223-249.

${ }^{41}$ Ibid., pp. 261-263. Sobre este personaje, vid., Alfonso María Guilarte, El obispo Acuña: historia de un comunero, ed. Miñón, Madrid, 1979.

42 Vid Avilés Fernández, ., Miguel, Sueños ficticios, o. c., pp. 111-116.
} 


\subsection{La mujer en el Sueño, de Juan Maldonado}

Si De motu Hispaniae presenta las características dichas, desde mi punto de vista, muy diferente se presenta Maldonado en Somnium, pero si relacionamos ambas obras nos pueden aportar unas claves nuevas.

El análisis del significado de "sueño ficticio" y las connotaciones que presentan como modo de eludir posibles represalias, así como la inserción de este Sueño concreto dentro de los relatos utópicos del Renacimiento es tema ya estudiado hace varias décadas, así como el análisis de los planos en los que se inserta el relato ${ }^{43}$, sin embargo, creo que no se ha relacionado alguno de los episodios relatados por Maldonado de las Comunidades, con el Sueño, cuya protagonista coincide.

En ningún caso puede considerarse arbitraria la elección de un personaje femenino para ser guía en el Sueño de Maldonado, ni lo es tampoco el nombre de la mujer, que fue real, Dońa María de Rojas (o de Osorio), hija de su protector, Diego de Osorio, que en su sueño aparece como María de Rojas o bien su referencia, cuando inicia el relato de su Sueño porque unas muchachas discretas le preguntan sobre le cometa, quizás alusión a su pupila, Ana Osorio, hija de María de Rojas, así como su larga disquisición sobre la aptitud de las mujeres para el cultivo de la sabiduría ${ }^{44}$, con lo cual, también en este caso una inicial ubicación femenina de su aventura onírica.

Diego de Osorio, casado con Isabel de Osorio, tuvo dos hijas, María Osorio (o de Rojas) y Ana Osorio. María se casó hacia 1504 con Pedro de Cartagena, señor de Olmillos y regidor de Burgos en el momento de las Comunidades. Pedro de Cartagena era descendiente de Pablo de Santa María, el conocido rabino judío, que llegó a ser obispo de Burgos ${ }^{45}$. Maldonado, relata siempre de modo muy especial todo lo relacionado con esta familia, los Osorio y los Rojas: vivió los aconteci-

${ }_{43}$ Miguel Avilés Fernández, Sueños ficticios, o. c., pp. 33-70, para la teoría general de los sueños y especialmente $p$. 107-178, para la obra de Maldonado (sigo esta edición, que incluye la traducción del Sueño en las pp. 149-178); id., "Utopias españolas de la Edad Moderna", Chronica nova: Revista de Historia Moderna de la Universidad de Granada, 13, 1982-1983, pp. 27-52, especialmente pp. 40-42, http://dialnet.unirioja.es/servletlejemplar?codi$g o=42026$ El Sueño, fue publicado por primera vez posiblemente en 1541 (por lo tanto 9 años después de la fecha en la que lo sitúa, 1532), vid., id., Sueños ficticios, o. c., pp. 107-108 y nota 3; Según Correa Calderón, Evaristo, Registro de arbitristas, economistas y reformadores españoles (1500-1936): catálogo de impresos y manusritos, Publicaciones de la Fundación Universitaria Española, Madrid, 1981, p. 163, tuvo una segunda edición en Lima, en 1646. Más recientemente se ha analizado este género desde distintas perspectivas, significativamente puede verse la obra colectiva Sabaté, Flocel (ed.), Utopies i alternatives de vida a l'Edat mitjana, Pagès editors, Lleida, 2009, especialmente para el tema aqui tratado, Heusch, Carlos, "Humanismo, mundo ideal y el sueño utópico en el siglo XV", ibid., pp. 275-292.

44 Vid. Avilés, Miguel, Sueños ficticios, o. c., p. 142.

45 Asensio, Eugenio, "Juan de Maldonado (c. 1485-1554) y su Paraenesis o el humanismo en la época de Carlos V", Id., De fray Luis de León a Quevedo y otros estudios sobre retórica, poética y humanismo, Ediciones de la Universidad de Salamanca, 2005, 251-313, las referencias a María de Rojas, en p. 263. 
mientos acaecidos en Burgos durante las Comunidades; describió a Osorio como contrapunto de su hermano el obispo Acuña ${ }^{46}$ y asistió al ataque de los comuneros a Diego Osorio e Isabel de Rojas, su esposa, el día 10 de junio de 1520, episodio que relata con todo género de detalles ${ }^{47}$, y se recrea como ningún otro cronista e historiador de Carlos I en los personajes relacionados con los Mota, los Rojas y los Osorio, citando repetidas veces a la mujer de éste:

Lo llevaron contra su voluntad y, tras dejar a su mujer, Diego de Osorio, aunque ponía de pretexto la noche que ya se echaba encima y otras cosas, rodeado del pueblo al punto que a la mula le costaba mucho avanzar en la multitud, se vio empujado primero a la casa de García Ruiz Mota, para que por orden suya fuera incenciada y destruida. García Mota era objeto de gran odio para los pecheros, porque había sido procurador en las Cortes de La Coruńa, y porque era hermano de Pedro Mota, obispo de Palencia, que en este tiempo tenía mucha influencia ante Carlos (...).

No pudieron empujar a Diego Osorio por fuerza o amenaza a que fuera a casa de Mota (...) Además, si su esposa e hijos no hubieran huido a escondidas por una puertat trasera hasta la casa de Osorio, habrían muerto arrojados a la misma hoguera con los colchones, tapices y lienzos ¡tan gran locura, tan gran demencia se había apoderado del común! ${ }^{48}$.

Asimismo Maldonado vivió la muerte prematura de Pedro de Cartagena y de María de Rojas, truncándose sus anhelos, pero también idealizando su imagen, a la que posiblemente amó en secreto, a tenor de su relato y de las veces que es citada en $D e$ Motu; asimismo es María de Rojas la que guía a Maldonado en su sueño por un mundo diferente que lo llevará a dos relatos muy distintos, uno acompañado por ella que se

${ }_{46}$ Maldonado, Juan, De motu Hispaniae, ed. cit., pp. 261-279.

47 Ibid., ed. cit., pp. 149-161. Ciertamente los nombres de María e Isabel de Rojas u Osorio a veces aparecen confusos, pero considero que la secuencia es la que he expuesto. Posteriormente Maldonado continúa el relato de los acontecimientos entre el obispo Acuńa y su hermano de forma pormenorizada, pp. 261-279; el relato de los acontecimientos de los Mota y Osorio en Burgos, es relatado mucho más brevemente por otros cronistas, entre ellos quizás el más expresivo es Fray Prudencio de Sandoval: "Era don Diego, a la sazón, corregidor de Córdoba, y había venido a ver a dońa Isabel de Rojas, su mujer, y a sus hijos. Despidióse luego de ellos, y aquella noche caminó para Córdoba, dejando encargada su casa a Pedro de Cartagena, señor de Olmillos, que estaba desposado con dońa María de Rojas, su hija, y al deán de Burgos, don Pedro Suárez de Velasco, que fue hijo del condestable, y a Francisco Sarmiento, que era su deudo. Estos caballeros acudieron luego a las casas de don Diego Ossorio y entraron dentro, y hallaron a su mujer y hijas con harto desconsuelo por la ausencia del dueño y temor de las amenazas del pueblo, que en sabiendo la ida de don Diego, se juntaron y vinieron con ánimo de entrarle la casa, y aun saquearla y echarla por el suelo", Sandoval, Fr. Prudencio de, Historia del Emperador Carlos V, o. c., II, pp. 29, 12-121 todo el relato, passim.

${ }^{48}$ Maldonado, Juan, De motu Hispaniae, ed. cit., pp. 153 y 155 respectivamente; Sobre este tema, vid., Morán Martín, Remedios, "Mercaderes burgaleses en la Guerra de las Comunidades", en István Szászdi León-Borja, María Jesús Galende Ruiz (Coords.), Carlos V: conversos y comuneros: Liber Amicorum Joseph Pérez, Centro de Estudios Camino de Santiago, Valladolid, 2015, pp. 485-498. Debe tenerse en cuenta que estas familias de mercaderes burgaleses llegaron a tener una considerable riqueza, de hecho, los Rojas tuvieron sepultura en la Catedral de Burgos, que aún se conserva en una de sus capillas. 
revela como una utopía lunar y otro, en el que lo deja solo, que es una utopía americana, casi contraste, de nuevo, entre lo utópico y lo real, aunque ambos sean imaginados.

Es el primero de los relatos, el lunar, el que me interesa resaltar de forma especial porque intuyo en él una continuada referencia a lo que podría haber sido utópicamente las aspiraciones comuneras, en el caso de haber prosperado y, siendo una sociedad ideal, al estilo de la propuesta en su Sueño, en ella podría desarrollarse su amor con María de Rojas. Obviamente, no existe en dicho relato alusión que pueda apoyar dicha aseveración, sino que debemos guiarnos por intuiciones tanto sobre el pensamiento de Maldonado, como del estilo literario elegido y el contenido del mismo, cuyos rasgos más significativos sería, comparando la realidad y la ficción.

Sitúa Maldonado el relato en el año 1532, en el que inició su docencia en Burgos en la cátedra de gramática, y a instancias de unas alumnas sale para observar el planeta: volvemos al entorno femenino en el que ubica Maldonado su relato; pero lo más significativo es que fue el año en el que pasó el cometa Halley, concretamente la noche del 14 al 15 de octubre ${ }^{49}$. A nadie se le escapa el significado que para el mundo medieval y del Renacimiento tenía la aparición de un cometa, sobre lo que siempre se creaban relatos fascinantes en torno al inicio de un nuevo ciclo, a la destrucción del viejo mundo y la aparición de uno nuevo, etc. Esto unido al significado de su relato ubicado en la luna, nos puede dar una pista interesante para considerar que, dentro del pensamiento del Renacimiento, es un síntoma del inicio de un nuevo mundo, de una nueva sociedad, que es en la que se adentra.

Pero, antes de aparecer el cometa, Maldonado recuerda el dechado de virtudes de María de Rojas:

Mientras vivió, aquella mujer había llevado en la tierra una vida auténticamente celeste. ¿A quién no llamó la atención su prudencia y su excepcional sentido práctico? ¿Quién no alabó su honradez, su franqueza, su incomperable lealtad? ¿Quién no reconoció en aquella hembra, enviudada en la flor de la vida, una perfecto ejemplo de acrisolada virtud? ¿Qién no se reconoció sorprendido por su constancia, su paciencia y su intrepidez en la adversidad? ${ }^{50}$

Para continuar sobre la presencia soñada de María, de nuevo utilizando el diálogo para la exposición, una vez hecha la introducción de los hechos:

Primero estuve divangando en sueños de acá para allá, hasta que, al final, se me hizo presente María de Rojas, vestida con la elegante negligencia con que lo hacía tras la muerte de su esposo.

\footnotetext{
49 Avilés Fernández, Miguel, Sueños ficticios, o. c., pp. 107.

${ }^{50}$ Maldonado, Juan, Sueño, ed. cit., p. 150. Aún sigue relatando varioss párrafos sobre la actitud de María de Rojas en torno a un pleito relacionado con la herencia de sus hijas.
} 
Su traje resplandecía de tal manera, brillaba tanto su rostro, centelleaban sus ojos y sus manos de tal forma que poco me faltó para creer que era una diosa quien estaba a mi lado. Seguro es que, si no la hubiese reconocido al primer golpe de vista, me habría postrado a adorarla ${ }^{51}$.

Puede decirse, dentro del claro platonismo de Maldonado, que su relato es la expresión de su amor platónico, en el que la amada se revela en todo su esplendor, llevándolo en volandas por el universo (sin trabas y libre de prejuicios) de los difuntos hasta la Luna, en la que contempla una ciudad ideal, con organización perfecta y perfecta armonía, quizás la que hubiera resultado de aunar intenciones comuneras y realistas, donde "Honran al rey; su mayor satisfacción es complacerle, pues le deben obediencia. Todos anhelan y aman las mismas cosas. Si uno se mueve, todos le siguen. Si aquél decide levantarse, ninguno se sienta. Les mueven los mismos gustos y coinciden en los mismos deseos. En suma, son las virtudes las que reinan allí y las que dominan lo mismo en los hombres que en las mujeres. No hay envidias ni discordias; allí, finalmente, todos los vicios están descartados y prohibidos" 52 .

Refugiado en el sueño, ajeno a su voluntad, por lo que también a cualquier acusación que se le pudiera hacer de relación sacrílega, pregunta qué puede desear y es María quien lo reconduce a su aristotelismo cristiano "Déjate de desear-replicó María- lo que no te ha de aprovechar y fíjate en lo que más puede encenderte en el amor de Dios" ${ }^{53}$, para llegar a comprender que nada le será permitido más allá del deseo, por lo que pide volver a la tierra, pero sin que lo abandone María ${ }^{54}$, lo que hace, para iniciar el segundo sueño en el Nuevo mundo.

\section{Una última evocación}

El SueÑo de Maldonado fue publicado en 1541, parece en cierto modo premonitorio del destino de una de las hijas de María de Rojas, Isabel de Osorio ${ }^{55}$, amante de Felipe II, posiblemente desde el año siguiente, 1542, puesto que todas las referencias lo vinculan con ella antes de su primer matrimonio con María Manuela de

54 “- Ilustre María, te lo ruego -dije-, no me abandones. Llévame antes a la tierra y déjame en cualquier luegar, desde donde pueda volver a mi patria. - No te abandonaré, no -respondió ella-, pues me lo piedes con tanta insistencia y a mí se me permite hacerlo", Ibid., p. 166.

55 Recientemente se está haciendo popular el género de novelas históricas que tienen como protagonistas a mujeres, entre ellas resulta fascinante la que se centra en Isabel Osorio, mujer de extremada belleza y cultura, a tenor de su estirpe de hombres de letras, la amante más permanente y fiel de Felipe II, claramente identificada y que fuera la musa para la serie de Danae pintada por Tiziano por encargo del rey, Domínguez, Mari Pau, Una diosa para un rey, Debolsillo, Barcelona, 2012, pp. 160-161, 198, passim.
} 
Portugal. La referencia desde el principio del Sueño de Maldonado a la casa de Pedro de Cartagena y a la muerte prematura de éste y de su mujer, María de Rojas, así como al destino de sus hijas, a las que evoca repetidamente, siendo una constante en el sueño de Maldonado, interpelando en varias ocasiones a María sobre qué debe decirles a sus hijas, siendo la respuesta de ésta de absoluta displicencia y libertad ${ }^{56}$, lo que representa una actitud enormemente avanzada para su momento, lejos de las pautas hasta entonces y hasta mucho después de entonces, indicadas para la mujer.

Lejos están las propuestas, casi coetáneamente, recogidas en la obra de Fray Luis de León, también conquense, La perfecta casada, que está dedicada a su sobrina María Varela Osorio ${ }^{57}$, siendo el contrapunto a lo hasta aquí analizado, pero de nuevo nos aparece una Osorio en el tema relacionado con la mujer en el siglo XVI; o asimismo la obra del también erasmista Juan Luis Vives, La mujer cristiana.

A veces, como en el Sueño de Maldonado, la imaginación vuela al ideal de amor que no pudo ser, no solo por el diferente papel social de los protagonistas (mujer casada y clérigo), sino por la muerte prematura de la amada, que acrecienta el ideal, quedándose el amante secreto prisionero, al estilo de Cárcel de amor de Diego de San Pedro ${ }^{58}$, que seguramente conocía el autor del sueńo, como se quedara también prisionera Isabel de Osorio, tras las rejas imposibles del amor regio.

\footnotetext{
56 "Mi deseo es -respondió- que si quieren casarse, que se casen; si prefieren la soltería, que sean solteras; si les da por el monjío, que sean monjas; que hagan, en una palabra, lo que decidan hacer”, Ibid., p. 171.

57 Desconozco si tiene alguna relación con los Osorio que aquí hemos referido.

58 San Pedro, Diego de, Cárcel de amor, Sevilla, por cuatro compañeros alemanes, 1492 (edición facsímil de Antonio Pérez Gómez, Valencia, Soler, Incunables Poéticos Castellanos, XIII, 1967), basada en la edición de Keith Whinnom, Obras completas, II. Cárcel de amor, Madrid, Castalia, on-line en Cervantes Virtual: 1980http:// www.cervantesvirtual.com/obra-visor/carcel-de-amor--0/html/fedfc8d4-82b1-11df-acc7-002185ce6064_2. html\#I_1_[fecha de consulta: 10/06/2019]
} 


\section{Referencias Bibliográficas}

Asensio, Eugenio, "Juan de Maldonado (c. 1485-1554) y su Paraenesis o el humanismo en la época de Carlos V", en Id., De fray Luis de León a Quevedo y otros estudios sobre retórica, poética y humanismo, Ediciones de la Universidad de Salamanca, 2005, pp. 251-313.

Avilés Fernández, Miguel, “Utopías españolas de la Edad Moderna”, Chronica nova: Revista de Historia Moderna de la Universidad de Granada, 13, 19821983, pp. 27-52, especialmente pp. 40-42, http://dialnet.unirioja.es/servlet/ ejemplar? codigo $=42026$.

Cátedra, Pedro, Del Tostado sobre el amor, Stelle dell'Orsa, Barcelona, 1986.

Cervera Vera, Luis, Francisco de Eiximenis y su sociedad urbana ideal, Col. Torre de la Botica, Swan, Real Sitio de San Lorenzo de El Escorial, MCMLXXXIX.

Cicerón, M. Tulio, Sobre la república, introducción, traducción, apéndice y notas de Álvaro D’ Ors, Ed. Gredos, Madrid, 1984

Correa Calderón, Evaristo, Registro de arbitristas, economistas y reformadores españoles (1500-1936): catálogo de impresos y manusritos, Publicaciones de la Fundación Universitaria Española, Madrid, 1981.

Domergue, Lucienne, "Goya, las Mujeres y la Guerra contra Bonaparte", en La Guerra de la Independencia en Málaga y su provincia (1808-1814), Servicio de Publicaciones del CEDMA, Málaga, 2005, pp. 231-248.

Domínguez, Mari Pau, Una diosa para un rey, Debolsillo, Barcelona, 2012

Fernández Jiménez, María Antonia, "La mujer en la guerra”, en España 18081814. La Nación en armas, Secretaría General Técnica del Ministerio de Defensa y Sociedad Estatal de Conmemoraciones Culturales, Secretaría General Técnica del Ministerio de Defensa y Sociedad Estatal de Conmemoraciones Culturales, Madrid, 2008.

Fuente, Ma Jesús y Morán, Remedios (Eds.), Raíces profundas de la violencia contra las mujeres (Antigüedad y Edad Media), Ed. Polifemo, Madrid, 2011.

García García, Heliodoro, El pensamiento erasmista, comunero, moral y humanistico de Juan Maldonado, Universidad Complutense de Madrid, Facultad de Filosofía y Ciencias de la Educación, 1983.

- El pensamiento comunero de Juan Maldonado, Madrid, 1983. 
Jerez, José Joaquín, Pensamiento político y reforma institucional durante la Guerra de las Comunidades de Castilla (1520-1521), Marcial Pons, Madrid, 2007.

Jiménez Bartolomé, Ana María, "Las mujeres en la Guerra de la Independencia: propaganda y resistencia", en Ocupació i resistencia a la Guerra del Francès (18081814), Biblioteca de Cataluña, Barcelona, 2005, pp. 247-256.

Madrigal, Alonso de, El 'De optima politia' de Alonso de Madrigal el Tostado, traducción y estudio preliminar de Juan Candela Martínez,

Maldonado, Juan, De motu Hispaniae. El levantamiento de España, Traducción, notas e introducción de María Ángeles Durán Ramos, Centro de Estudios Constitucionales, Madrid, 1991,

Maldonado, Juan La revolución comunera. El movimiento de España, o sea historia de la revolución conocida con el nombre de las comunidades de Castilla, escrita en latín por el presbitero Juan Maldonado y traducida e ilustrada por el presbitero don José Quevedo, bibliotecario del Escorial, 1840 (existe nueva edición con introducción de Valentina Fernández Vargas, Ed. Centro, Madrid, 1975);

El "De motu Hispaniae" de Juan de Maldonado, estudio y edición crítica de Manuel Martínez Quintana, Editorial Universidad Complutense de Madrid, 1988 (Tesis doctoral, Departamento de Filología clásica, Facultad de Filología, UCM, 2015, está en pdf en el repositorio de la UCM)

Maldonado, Juan, Sueño, traducción castellana (Ed. de Miguel Avilés, Sueños ficticios y lucha ideológica en el Siglo de Oro, Editora Nacional, Madrid, 1980, pp. 149-178, con estudio introductorio, pp. 107-148.

Maravall, José Antonio, Las Comunidades de Castilla, Alianza Universidad, Madrid, 1981, 3a ed.

Martín, José Luis, La mujer y el caballero: estudio y traducción de los textos de Francecs Eiximenis, Edicions Universitá de Barcelona, 2003.

Martínez Gil, Fernando, La ciudad inquieta. Toledo comunera. 1520-1522, Instituto provincial de Investigaciones y estudio toledanos - Diputación provincial de Toledo, 1993.

Mendonça, Manuela, "Uma mulher no exílio: María de Padilha e Portugal", en Monarquía y revolución: en torno a las Comunidades de Castilla. I Simposio Internacional de Historia Comunera, Valladolid, 2009, pp. 259-275.

Mexía, Pedro, Historia del Emperador Carlos V, escrita por su cronista el magnifico caballero --, Ed. y estudio de Juan de Mata Carriazo, Espasa Calpe, Madrid, 1945. 
Montero Ballesteros, Alberto, "El 'Tractado de Republica' de Alonso de Castrillo (1521)", Revista de Estudios Políticos, 188, 1973.

Morán Martín, Remedios, "Mercaderes burgaleses en la Guerra de las Comunidades", en István Szászdi León-Borja, María Jesús Galende Ruiz (Coords.), Carlos V: conversos y comuneros: Liber Amicorum Joseph Pérez, Centro de Estudios Camino de Santiago, Valladolid, 2015, pp. 485-498.

Muñoz Fernández, Ángela, "Introducción”, en Las mujeres en el cristianismo medieval, Ed. Laya, Madrid, 1989

Pérez Rubio, Alberto, "La mujer y la guerra en el Occidente europeo (siglos III a. C.-I d. C)", en Jordi Vidal y Borja Antela (eds.), Más allá de la batalla. La violencia contra la población en el mundo antiguo, Libros Pórtico, Zaragoza, 2013, p. 97-126

Pérez-Prendes, José Manuel, "El mito de Friné", en Cuadernos de Historia del Derecho, Cuadernos de historia del derecho (en homenaje a don Manuel Torres López.) 6, I y II, 1999-2000, pp. 211-232.

- "El mito de Friné. Nuevas perspectivas", en Anuario de la Real Academia de Bellas Artes de San Telmo no 5, 2005, pp. 33-46.

— “Génesis, 2.25”, en Fuente, Ma Jesús y Morán, Remedios (Eds.), Raíces profundas de la violencia contra las mujeres (Antigüedad y Edad Media), Ed. Polifemo, Madrid, 2011, pp. 407-432

- "María Pacheco, comunera por otro entusiasmo", en Szaszdi León Borja, Istvan y Galende Ruiz, María Jesús, Imperio y tiranía. La dimensión europea de las Comunidades de Castilla, Universidad de Valladolid, 2013, pp. 385-410.

Plutarco, Las vidas paralelas, III, traducidas de su original griego al castellano, por el consejero de Estado D. Antonio Ranz Romanillos, Imprenta Nacional, Madrid, 1822.

Reder Gadow, Marion, "Mujeres en las Barricadas durante la Guerra de la Independencia (1808-1814): la rondeña María García 'La Tinajera”, en Dossiers feministes, 15, 2011 (Ejemplar dedicado a: Mujeres con mayúsculas. Barricadas, salones y escritorios (siglos XVII-XIX), pp. 9-25

Rodríguez Horillo, Miguel Ángel, "Las Historias de Salustio y los acontecimientos del año 75 a. C. en Hispania (fragmento I 125, II 89-97 M)", en Palaeohispanica 12, 2012, pp. 109-139.

San Pedro, Diego de, Cárcel de amor, Sevilla, por cuatro compañeros alemanes, 1492 (edición facsímil de Antonio Pérez Gómez, Valencia, Soler, Incunables Poéticos Castellanos, XIII, 1967), basada en la edición de Keith Whinnom, Obras completas, II. Cárcel de amor, Madrid, Castalia, on-line en Cervantes Virtual 
Sandoval, Fr. Prudencio de, Historia del Emperador Carlos V, rey de España, La Lectura. Biblioteca de obras selectas, bajo la dirección de D. Gregorio Urbano Dargallo, Madrid, 1846

Smith, Paul Stephen, A humanist history of the "Comunidades" of Castile: Juan Maldonado's De motu hispaniae, University of British Columbia, 1987 https:// circle.ubc.ca/handle/2429/26922?show=ful

Tácito, Cayo Cornelio, La Germania, Trad. de Carlos Coloma, M. Aguilar editor, Madrid, 1945.

Tamayo Acosta, Juan José, "Las fuentes religiosas cristianas: La Biblia y los padres de la Iglesia”, en Fuente, $\mathrm{M}^{\mathrm{a}}$ Jesús y Morán, Remedios (Eds.), Raices profundas de la violencia contra las mujeres (Antigüedad y Edad Media), Ed. Polifemo, Madrid, 2011, pp. 27-44

Vigil, Mariló, La vida de las mujeres en los siglos XVI y XVII, Siglo XXI, Madrid, 1986;

Zúńiga, Francesillo de, Crónica burlesca del emperador Carlos V, Edición, introducción y notas de Diane Pamp de Avalle-Arce, ed. Crítica, Barcelona, 1981

DOI: http://doi.org/10.15366/bp2019.22.026

Bajo Palabra. II Época. № 22. Pgs: 477-500 